\title{
Editorial
}

doi:10.1017/S0954102015000061

\section{Failing to learn from inspections}

A ntarctica is a self-policing continent where the nation-states that work there apply national A laws to their activities. Many of these laws and regulations are based on recommendations agreed at the Antarctic Treaty Consultative Meetings. The suspicion that not every state would behave properly unless there were some checks underlay the original agreement of Article VII in the Antarctic Treaty, establishing the right to international inspections of stations, ships and aircraft. Of course, back in the 1950s when this was negotiated, the intent was to ensure that neither the United States nor the Soviet Union could militarise their Antarctic facilities, especially by the installation of ballistic missiles.

Those days of the Cold War are long past but the value of inspections lives on, albeit in a rather different format. Although the original military reason for inspections is still valid the present focus has been on environmental considerations, especially since the agreement on the Madrid Protocol in 1991.

At the XXXVII ATCM in Brasilia nine countries, led by the UK, put forward Working Paper 37 which drew some thematic conclusions out of an analysis of the last ten years of inspection reports. This decade of inspections had involved inspectors from 15 countries visiting over 50 stations (some several times), 10 ships, 13 Historic Monuments and 8 Antarctic Specially Protected Areas. This was a substantial effort by over half of the Consultative Parties and included most of the principal stations on the continent. A good basis therefore from which to draw conclusions. The inspection reports had all been presented and discussed at previous meetings, the conclusions were couched in general terms and the suggested actions were requests to SCAR and COMNAP or proposals to promote sharing of resources and information. All of this seemed unexceptional and useful. So why did this sensible piece of work produce a lengthy and fruitless discussion in the course of which virtually all the proposed actions arising from these expensive inspections failed to elicit unanimous support and action?

The problems lay in the implication that those inspected were expected to respond to criticisms and report to the ATCM on what they had done to correct the problems identified. As was pointed out, inspections were expensive to undertake and it seemed therefore a little impolite for a Party to ignore helpful advice on how to improve their station management. However, some Parties argued that this made it appear that the recommendations by inspection teams were not simply advisory and that any enforced reporting on responses infringed national sovereignty. Such a legalistic approach completely overwhelmed the sensible nature of the paper's proposals so that suggestions on improving safety by installing fire alarms, improving efficiency by sharing internet bandwidth, power generation and water supplies, as well better environmental management of wastes and waste water all were ignored. About the only element that was agreed was for the Secretariat to archive inspection reports and any related papers in such a way that they could be searched for by station.

The success of the Treaty over the past 60 years has, in no small part, been due to the freedom to inspect, assuring politicians in all countries that the Antarctic is only being used for peace and science. Using the same procedure to determine how well the signatories to the Madrid Protocol are meeting their legal obligations to protect Antarctica for future generations is simply a step further along the way. One can only hope that those 15 countries that have undertaken inspections will talk to their recalcitrant colleagues and return to the subject in the future in order to action the eminently sensible recommendations.

D.W.H. WALTON 